\title{
Discussion about Advantages of Tropical Coastal Tourism Cities in Development of Marine Economy
}

\author{
Sicong Shen ${ }^{1, a}$, Xuebin Huang ${ }^{1, b}$ and Kun Zhang ${ }^{1,2, c^{*}}$ \\ ${ }^{1}$ Education Center of MTA, Hainan Tropical Ocean University, Sanya, Hainan, 572022, China \\ ${ }^{2}$ College of Ocean Information Engineering, Hainan Tropical Ocean University, Sanya, Hainan, 572022 , \\ China \\ a sicong0721@163.com, bpu.huang@qq.com, ${ }^{\text {*c }}$ zk0588@163.com \\ *The corresponding author
}

Keywords: Tropical coastal tourist city; Marine economy; Seashore tourism; Sustainable development

\begin{abstract}
Its unique resources of climate and geography add Sanya much more charm and tourism income. However, these external resources can not completely meet the requirement of rapid development in Sanya especially at the present time when it has not only been a slowdown in world economy growth and tourism, but also the competition stress becomes fierce within different regions and industries. Nobody knows how long we can still depend on our unique natural environment. According to the development conception, "the Belt and Road," which Chairman Xi put forward in 2015, Sanya now is taking great responsibility to build a modern "The South China Sea Silk Road" and there is also a mission of deeply developing marine economy of South China Sea, based on its special regional conditions and tourism.
\end{abstract}

\section{Introduction}

Sunshine from 18 degree of northern latitude, gentle breeze, bird-view of creeping waves, girls with hot bikini in drinking coconut juice under thatched umbrella on beach-all scenes seem to be defined as city card of coastal tourism city early, every tourist could filled with eagerness and envy before packing traveling bag up, which also becomes primitive and original attraction for tourism destination.

Unique climatic resources and geographical resource truly add charms and increase incomes for Sanya, but the tourism industry falls on the whole with white-hot competition pressure among regions and industry today in context of currently slow growth of global economy entirely, these apparent utilization of resources couldn't satisfy the rapid economic development in Sanya, no one could know how long natural resources could promote economic development. Up to now, we should explore the sophisticated development course with more potentials and long-term meaning based on fields of sciences, technologies and humanity behind these resources. In order to reach this end, Sanya makes best use of unique geographical location and solid foundation of tourism development with combination of major initiatives about Economic Belt of Silk Road and Maritime Silk Road in 21st century to bear important task of Silk Road Tours of the South China Sea and shoulder mission of in-depth development of marine economy of the South China Sea at the same time. Sanya also extends greeting to new chances and challenges in historical development based on solid foundation of coastal tourism industry. But gone is the performance of tourism industry, in context of global background and stimulation and call of global environment, the economic growth in Sanya still needs to go towards direction in width and depth with brave and strong action.

\section{Advantages of Tropical Coastal Cities for Developing Tourism Industry}

Developing coastal tourism industry could be regarded as first task and foundation for tropically coastal cities to develop marine economy. How to seek the best channels for development of coastal tourism 
industry. The author holds the opinions that copinism is indispensable in Sanya with occupying advantageous climatic resources and geographical resources. Our development of coastal tourism industry seems to be comparatively superficial and young as compared with excellent foreign islands and coastal tourism industry, there is lots of rooms for improvement of sophistication and individual development of tourism industry. Let us take Dubai and Hawaii as an example-world-famous tourism city of tropical bay and tropical coastal tourism city full of exotic customs, although there is lots of common climatic resources with Sanya, the two destinations generally seem to be better than Sanya in China as results of development foundation and mature level, so we are able to learn lessons from them with reference. What Dubai leaves people the impression is that this is the luxurious and high-end place where rich people gather, there are most luxurious super seven star Burj Al Arab, highest Burj Khalifa Tower and biggest shopping center in the world $\cdots$ these things are far from enough to say, mysterious religious dress, endless desert with wisp of smoke, the extremely natural phenomena about comparison of bay and desert-mysteriously and naturally. Maybe we could not compare us with well-being of Arab States, we could learn lessons from their success-developing tourism economy with their own characteristics, integrating elements of characteristics will always need perfect connection of regional culture and geographical resource as well as climatic resources. In daytime, the golden light will shine through Dubai which will seem to sparkling in the night, what could bedazzle your eyes is to grovel bonfire and loose pulley as well as go shopping in flavor street and dance performance. The charm of Dubai is more than luxury simply.

When it comes to Hawaii, as the precursor in island tourism, Hawaii has lots of common things with Sanya in geographical location as results of locating in tropic, Sanya is necessary to learn lessons of development about Hawaii because Sanya plans to go towards development direction of oriental Hawaii. The Hawaii style is defined to be wild, hot and indigenous, which could be explained by its inclusiveness, Hawaii experienced from early life in original Kapu system, then colonization from many countries and finally conversion to United States of America, which undoubtedly brings openness, inclusiveness and passion to Hawaii. Hot beach parties, cool Martini and exotic Hawaiian dance will be served as symbols of Hawaii to attract attention from tourists and visitors in the world for detailed experience. Therefore it is obviously to see what the tropical coastal cities have something in common and disparity of development at the same time. One city will not develop without its inherent connotation and culture, which could be considered as inherent driving force for economic development, Dubai or Hawaii, the cities could rely on such human elements as nationality, faiths and folk customs, although unique climatic resources and geographical resources are very important, all glories will seem to be very weak and lifeless without backgrounds of human culture, human interest and popularity. Therefore Sanya should learn lessons of success and inject such elements into internal tourism industry as island culture, culture of national minority, life and production to develop tropical coastal tourism with characteristics and regional tourism. The culture of Miao and Li minorities should not stay themselves on tourism scenic spot, the fisherman ecology should not disappear with any tracks, the urbanized construction should not copy from hinterland, which could be vividly described in that sentence: the features derived from nations from the world is forever. The charms of tropical coastal tourism cities lie in unique climate and landscape, especially unique marine culture. So conclusion should be that developing tourism culture in match with tourism industry will hold the key to explore development course of tourism economy.

\section{The Advantages of Marine Resources for Economic Growth of Tropical Coastal Cities}

The sustainable development and exploitation of marine resources could be served as driving force and potentials for developing coastal urban economy. Something in Marine Economic Development Plan of the South China Sea in 2016 has been pointed out that marine economic development lacks macro guidance, coordination and plan; traditional marine industry still stays themselves in development stage of extensive use so that what enters into market is preliminary products; emerging marine industry will have difficulty in 
development due to generally low level of marine technologies; weak competition edge in attracting modern large-scale enterprises and great difficulty in inviting investment; right disputes becomes increasingly complex concerning sea area of the South China sea to influence development of marine resources; marine fishery is influenced greatly by signing Sino-Vietnamese North Gulf Demarcation Agreement and Sino-Vietnamese North Gulf Fishery Cooperation Agreement; ecological environment in coastal breeding area are polluted to a certain extent, and more over the ecological system of mangrove forest and coral reef also undergoes destroy. Based on analysis in plan, there is easy for us to see that development of marine economy in Hainan province still remains at very low level. However, the resources in Hainan province should not be ignored; there are lots of kinds of natural resources in coastal regions and sea area of Hainan province, which is suitable for development of marine economy. According to incomplete statistics, there are more than 600 islands, continents, reefs and beaches; the coastline extends 1928 kilometers in total length in whole province with 0.05453 coastline coefficient, Ranking the second in the whole country, among these islands, the coastline of Hainan Island extending 1618 kilometers in total length with 0.0477 coastline coefficient higher than average national level of coastline coefficient; Huanben island has 84 harbors with only 68harbor ready for development; such harbors could boast extensive covering area ,deep sea water and broad hinterland as Yangpu, Haikou, Qinglan, Sanya and Basuo, which is available for harbor construction; there are rich oil-gas resources in surrounding sea area of Hainan province, which could be calculated to more than 20 billion tons in total reserves of oil-gas resources, ranking top one in the whole country, the natural gas hydrate resources could be reserved in north central sea area of the South China Sea. The proved geological reserves of crude oil accounts for 0.58779 billion tons in sea area of the South China Sea with remnant 49.21 million tons for exploitation by the end of 2002. The proved geological reserves of gas condensate reaches to 5.359 million tons with remnant 3.529 million tons for exploitation. The proved geological reserves of gas from air layer is accumulated up to 257.739 billion cubic meters with remnant 163.254 billion cubic meters for exploitation. The proved geological reserves of solution gas is 13.909 billion cubic meters with remnant 2.487 billion cubic meters for exploitation. The proved geological reserves of oil-gas resources accounts for less than $1 \%$ total reserves in surrounding sea area of Hainan province. There are more than 600 kinds of offshore fishery resources in Hainan island and more than 1000 kinds of fishes in Xisha, Nansha and Zhongsha islands, in which there are more than 40 kinds and 80 kinds with high economic values, shallow sea with intertidal zone and water depth of 20 meters enjoys total covering land of 55.68 million square meters; there are 241 scenic spots in the whole province, in which there are 123 developed scenic spots, while 83scenic spots is located in coastal zone accounting for $67 \%$ total scenic spots, there is great potentials in developing tropical coastal tourism and recreational tourism on island; there are more than 80kinds of coastal sand mineral resources in which reserves of ilmenite and zirconite are 7.617 million tons and 1.296 billion tons respectively, accounting for more then $1 / 4$ and 1/3 same-type mineral reserves in the whole country. When it just comes to Sanya, such development of resources industry is very urgent as marine fishery, sea salt industry, marine oil and gas industry for Sanya. Objectively speaking, the strategical position of Sanya and the South China Sea truly seems to be subtle and sensitive, for which the state has many thoughts and consideration based on every aspect, especially sea area in Sanya is near Southeast Asia region and thus becomes important place receiving attention from all over the world. Which brings about difficulty and hindrance for Sanya and the South China Sea as well as chances. Although offshore fishing in Sanya keeps themselves in primitive development stage, Sanya still boasts rich indigenous seafood and fishery resources with great quality. The development of marine fishery left behind with low level due to transportation, delivery and technologies, now we could rely on policy environment of One Belt and One Road to attract more talents for development and innovation on deep-sea fishery and marine food, so is sea salt industry. In recent years, sea salt receive extensive attention and with increasingly recognition than ever before, Sanya could make best use of wave to develop sea salt processing and production and processing of sea salt-related foods, thus gaining marine economic growth. Currently the oil-gas industry could be irreplaceable. As the development 
of the industrial revolution, China's economy could achieve rapid and vigorous development, and moreover extensive use of energy resources will result in harmful consequence for economy, environment and resources as well as bring crisis for next generation during past 40 years. The development of marine oil and gas resources seems to very urgent, and in the meanwhile what bears the brunt is to prevent marine oil and gas resources from violation and robbery.

\section{Advantages of Technological Development of Tropically Coastal Tourism City}

The combination of production, teaching and research will be internal requirement and inexhaustible driving force of currently economic growth in current marine economy. In April 2016, what has been brought forward in 13th Five Year Plan of Marine Economic Development for Sanya is that Sanya will be built into city with one valley, two places, three areas and four centers since the end of 2020, namely a series of constructions should be worked out in establishing tropically blue valley with the characteristics of Sanya, tourist attraction with tropical ocean and rescue base of the South China Sea; establishing state-level civilized demonstration area of marine ecology, pilot area of innovation and reform of comprehensive marine management and tourist area of tropical marine sports; establishing development centers of Asian cruise ship, yacht and Sailing ship, domestically modern marine fishery center, domestic marine center of science, education and culture as well as cutting-edge marine transportation center of the South China Sea. Every sentence in plan could be nowhere without combination of production, teaching and research. Developing modern marine economy could get nowhere without science, much less the innovation, which will embrace the bright future and seize more chances under innovation-driven newly-type marine economy. The common development trend of global coastal cities is to establish hi-tech industry park, typically reflecting in the valley of United States and Tsukuba in Japan, while China's coastal cities will follow suit such as Qingdao. As only one of tropically coastal city in China, Sanya establishes hi-tech industry park based on universities in such important geographical location, which is irresistible trend and solution for development. Hainan Tropical Ocean University is served as incubation base of high-tech Industry Park with collaboration with local tourism industry and deep-sea research institution on behalf of other universities in Sanya, the research results will be turned into productivity through enterprises. The production in combination of production, teaching and research should not only refer to industry, but also be available for service industry. For example the promising one in marine tourism industry and marine transportation industry-economic of cruise line, institution of higher learning and research institution could carry out detailed analysis and research on service of cruise ship with their own advantages based on supports from funds of cruise industry, comb out development course of modern service industry and modern marine economy through feasible reports and project development plan, explore the development direction of China's cruise ship, domestic air line \&international air line and repeat the deliberation after re-entry into market so as to form tourism products finally. In addition, the combination of production, teaching and research could be fully delivered to important part of economic growth so as to promote openness of tourism industry and tourism cooperation of cruise ship on Maritime Silk Road in 21st century, efforts should be made to make international cruise ship phoenix Island in Sanya become testing harbors for berth, the airline of cruise ship in the South China Sea could be created to bring about the great international tourism with the cruise; the active efforts should be made on holding international competition, international forum, international convention and exhibition to promote international influence; based on resources advantages and current situation, we should carry out in-depth development of tourism industry of water sports and industry of low altitude flight as well as design safe and environment-friendly large-scale water performance platform with real landscape and innovation of water tourism industry, however which has been established on basis of combination of production, teaching and research. The development of industry without scientific research could be no longer suitable for development of era. 
In addition, the tropically agricultural resources (the tropical fruits could be best) and forest resources could be called characteristics in Sanya, but with outdated cultivation and operation pattern, there is disparity from domestic places of fruit production, we could learn from Guangxi and Taiwan regions to fully development and innovate cultivation so as to raise greatly yields and quality as well as improve ability of matched parcel and delivery, thus leading to fruits with brands, sightseeing agriculture and sightseeing forest.

\section{Summary}

The charms of Sanya should not focus on sunshine and beach only, the development of marine economy should not stay themselves on development of fishery resources, One Belt and One Road brings historical opportunity to Sanya and biggest challenges to people in Sanya so far. We could only seize the chances and stay true to ourselves so as to explore more scientific and efficient development course of marine economy.

\section{Acknowledgement}

This research was financially supported by the Hainan Province Tourism Management Key Disciplines Construction Project; the MTA Teaching Reform Research Project (No. MTAJG2016-07); the Hainan Planning Projects of Philosophy and Social Sciences (No.HNSK (QN)15-60); the 2016 Hainan Education Science Study Topics of the "13th Five-Year " Plan (No.QJY13516030).

\section{References}

[1] Jian LI, Xin TENG, Explore the Development of Marine Economic Cycle Model, Popular Tribune, No.02, pp.4-6, 2011.

[2] Hainan reporter station, Beautiful and Unique Charm of the International Tropical Coastal Tourist City - Sanya, China Information News, 2016.03.10,(012).

[3] Dongzhou JIANG, Speed Up the Transformation and Development, Comprehensively Construct the Internationalized Tropical Coastal Tourism Boutique City - Interview with Zhang Qi, Member of Standing Committee of Hainan Provincial Committee and Secretary of Sanya Municipal Committee, Science and Technology Daily, 2016.03.04,(007).

[4] Jieyu LI, Dilemma and Outlets for Marine Economic Development in Hainan, Journal of Hainan Normal University(Social Sciences), Vol.26, No.12, pp.112-116, 2013.

[5] Mu YUAN, Xiaoguang ZHANG, Ming YANG, English and Innovation in Urban Strategic Planning Based on SWOT Analysis, City Planning Review, Vol.31, No.04, pp.53-58, 2007.

[6] Kun Zhang, Hong-Xu Wang, Hai-Feng Wang and Zhuang Li. The Time Series Prediction Algorithm of Enrollment based on the Hesitancy degree Correction Rule of Vague Sets, ICIC Express Letters. 2015, Vol.09, No.05, pp.1311-1318.

[7] Minsheng LIAO, Kun ZHANG, Hongxu WANG, Zhuang LI, Haifeng WANG, Research on Forecasting the Quantity of Tourists in Sanya City, Economic Research Guide, No.01, pp.239-243, 2015.

[8] Minsheng LIAO, Kun ZHANG, Hongxu WANG, Zhuang LI, Haifeng WANG, Forecasting Total Tourism Income of Sanya Based on Fuzzy Time Series Model, Economic Research Guide , No.04, pp.237-242, 2015. 
[9] Songjiang CAO, Pingbin JIN, Chunqin HU, Factors of Marine Tourism Economic Development in Zhejiang Province Based on PCA and Multivariate Regression Analysis, Journal of Xinjiang Normal University(Natural Sciences Edition), Vol.35, No.03, pp.1-7, 2016.

[10] Miao WANG, Nuosi WANG, A Summary of the Research on the Integration of Ocean Culture and Tourism Economy at Home and Abroad, Journal of Dalian Maritime University(Social Science Edition), Vol.15, No.03, pp.7-11, 2016. 